\title{
Physical functioning after occupational rehabilitation and returning to work among employees with chronic musculoskeletal pain and comorbid depressive symptoms
}

\author{
This article was published in the following Dove Press journal: \\ Journal of Multidisciplinary Healthcare \\ 23 January 2014 \\ Number of times this article has been viewed
}

\author{
Linda Ernstsen' \\ Monica Lillefjell ${ }^{2}$ \\ 'Faculty of Nursing, Sør-Trøndelag \\ University College, Trondheim, \\ Norway; ${ }^{2}$ Department of \\ Occupational Therapy, Faculty of \\ Health Education and Social Work, \\ Sør-Trøndelag University College, \\ Trondheim, Norway
}

\begin{abstract}
Background: The aim of this investigation was to assess whether measures of physical functioning after multidisciplinary rehabilitation are associated with return to work among individuals with chronic musculoskeletal pain conditions and comorbid depressive symptoms.

Methods: Included were 92 employees with chronic musculoskeletal disorders who had participated in a 57- week multidisciplinary rehabilitation program. Their ages ranged from 25-59 years. The Hospital Anxiety and Depression Scale was used to assess depressive symptoms. Different aspects of physical functioning (muscle strength, mobility, endurance capacity, and balance) were measured with single-item visual analog scales, and physical fitness was measured with the validated COOP/WONCA charts. Being on "active work strategies," such as receiving rehabilitation benefit/vocational rehabilitation or being reported partly or completely fit, was defined as "on their way into/in work". Cross-sectional associations were measured using logistic regression models, estimating odds ratio with $95 \%$ confidence intervals.

Results: There were no differences between the "on their way into/in work" group ( $n=70)$ and the "on their way out/out of work" group $(n=22)$ regarding age, sex, or levels of anxiety or pain. Surprisingly, regression analyses showed that those with higher levels of physical functioning had significantly lower odds of returning to work.

Conclusion: The findings of an inverse relationship between self-reported physical function and returning to work in this sample illustrate that the return-to-work process among employees with chronic musculoskeletal pain and comorbid depressive symptoms is multifactorial and influenced by factors other than physical functioning at the individual level. Further research, especially longitudinal studies, is needed to assess the occupational trajectories among employees with chronic musculoskeletal pain and comorbid depressive symptoms after participation in a multidisciplinary rehabilitation program.
\end{abstract}

Keywords: chronic musculoskeletal pain, multidisciplinary rehabilitation, physical functioning, depression, return to work

\section{Introduction}

In Norway ${ }^{1}$ and most Western societies, ${ }^{2}$ the major causes of long-term sick leave and work disability are chronic musculoskeletal and mental disorders. The numbers of disability pensioners are increasing and this represents a large economic burden for society. In addition, not being able to participate in the labor force has negative consequences for the individual. Depression is the leading cause of disability ${ }^{3}$ and has a more negative prognosis for return to work (RTW) than other common mental health conditions. ${ }^{4,5}$
Correspondence: Linda Ernstsen Faculty of Nursing Education, Sør-Trøndelag University College, NO-7004 Trondheim, Norway Tel +47 72575625

Email linda.ernstsen@hist.no 
Somatic symptoms and depression often coexist, ${ }^{6}$ and epidemiological findings support that there is a bidirectional association between depression and chronic musculoskeletal conditions. ${ }^{7}$ Further, studies suggest that depression contributes to poor RTW in individuals referred to occupational rehabilitation, even controlling for pain severity. ${ }^{8}$ Chronic pain is a common long-term condition that affects a person's physical and emotional functioning. Approximately $20 \%-50 \%$ of individuals with musculoskeletal conditions show evidence of elevated depressive symptoms, further suggesting that comorbid depression is associated with poorer rehabilitation outcomes. ${ }^{8,9}$

Multidisciplinary rehabilitation approaches have been shifting away from a restricted biomedical model toward a multifactorial model of interrelating physical, psychological, and social/occupational factors, ${ }^{10}$ with emphasis on function and work ability, disability management, and psychosocial interventions. Results support that participation in multidisciplinary rehabilitation programs increases quality of life and decreases anxiety and depression in employees with musculoskeletal disorders. ${ }^{11}$

Several studies suggest that physical factors, such as improvements in strength, endurance, or flexibility, appear to have little relation to RTW rates after interdisciplinary treatment. ${ }^{12,13}$ Other studies confirm that increased depressive symptoms are associated with decreased physical functioning. ${ }^{14,15}$

In a recent review, McKnight and Kashdan ${ }^{16}$ stated that there is little research directly examining the relationship between depressive symptoms and physical ability. The extent to which employees with chronic musculoskeletal disorders and depressive symptoms successfully adapt back into their job roles after participating in a multidisciplinary rehabilitation program remains unclear. Given the association between chronic pain, depression, and physical function, ${ }^{16,17}$ it is likely that RTW in persons with chronic musculoskeletal pain and comorbid depression would be associated with better physical functioning.

The aim of our investigation was to assess whether various measurements of physical functioning among persons with chronic musculoskeletal pain and comorbid depression were positively associated with RTW after participating in a 57-week multidisciplinary rehabilitation program.

\section{Materials and methods}

\section{Participants}

Participants with a long-term history of mixed chronic musculoskeletal pain were recruited by their general practitioners, who assigned them to a 57-week multidisciplinary rehabilitation program on the basis of interviews, observations, and clinical tests. Inclusion criteria for participation in the rehabilitation program were that the participants had chronic musculoskeletal pain (longer than 3 months) and were receiving national insurance in the form of sickness benefit or rehabilitation benefit.

In Norway one can start drawing a retirement pension at the age of 62. To ensure that none of the participants were in any initial phase of retirement, we excluded those aged 60 years and older. Further, to assess any difference in physical function and return to work among those with comorbid depressive symptoms at the end of the rehabilitation, we included only those with high depressive symptoms measured by the Hospital Anxiety and Depression Scale (HADS).

Data were routinely collected from November 2003 until January 2008. The Regional Committee for Ethics in Medical Research approved the protocols of the study. The participants provided written consent.

\section{The multidisciplinary rehabilitation program}

To maintain the right to financial support in the form of sickness or rehabilitation benefits from the National Health Insurance Office, an assessment of function and work capacity is required. Our rehabilitation program, funded as purchasing health services, offered the required assessment. General practitioners recruited participants into the 57-week rehabilitation program in cooperation with the National Health Insurance Office, in order to obtain a function and work capacity evaluation as required.

In cooperation with the Public Health Services, National Health Insurance Office, Employment Office, and the employer, an individually tailored rehabilitation program was conducted. The rehabilitation program included both individual counseling and group-based treatment, including physical components (see Table 1). The program consisted of 1) a 5-week intensive period that the participants attended approximately 6 hours a day, 4 days a week, and 2) a follow-up period of 52 weeks that the participants attended approximately 6 hours a day, 1-3 days a week.

\section{Hospital Anxiety and Depression scale}

Symptoms of anxiety and depression were assessed using the HADS, a self-rating scale commonly used for screening purposes in various clinical settings and in epidemiological studies. ${ }^{18}$ The symptom scale consists of seven items that cover anxiety and seven items that cover depression on a 4-point Likert scale. No somatic items 
Table I Content of the 57-week multidisciplinary rehabilitation program

\begin{tabular}{|c|c|c|}
\hline Period & Intervention & Duration \\
\hline $\begin{array}{l}\text { Period I: mapping } \\
\text { of the participants' } \\
\text { resources; intensive } \\
\text { training period }\end{array}$ & $\begin{array}{l}\text { - Introduction to the rehabilitation program. } \\
\text { - Mapping physical-, psychological-, and social functioning (personal capacity) using } \\
\text { I) standardized instruments and 2) personal interviews. } \\
\text { - Individual counseling based on the mapping and interviews; focus on strengthening existing } \\
\text { resourses in preparation of a long-term plan for the rehabilitation process in cooperation } \\
\text { with their general practitioner, social security officer, and the employer. } \\
\text { - Individual and group-based training to improve personal capacity and strengthen existing } \\
\text { resourses: I) individual exercise program with focus on facets such as endurance, strength, } \\
\text { mobility, and relaxation techniques; 2) group-based education/training in different health- } \\
\text { related subjects eg, body structure, diet, exercise planning, coping strategies, communication, } \\
\text { strategies for conflict negotiations, and information about the social security system; } \\
\text { and 3) indoor and outdoor activities every day. }\end{array}$ & $\begin{array}{l}6 \text { hours a day, } \\
4 \text { days a week } \\
\text { for } 5 \text { weeks }\end{array}$ \\
\hline $\begin{array}{l}\text { Period 2: follow-up } \\
\text { training; rehabilitation } \\
\text { period }\end{array}$ & $\begin{array}{l}\text { - Mapping physical, psychological, and social functioning (personal capacity) using standardized } \\
\text { instruments and personal interviews at the start and at the end of period } 2 \text {. } \\
\text { - Functional capacity training (individual and group-based, indoor/outdoor, education) continues. } \\
\text { - Individual counseling; assisting the patient in the rehabilitation process, coordinating the } \\
\text { rehabilitation process, informing about resources and limitations in use of policy instruments. } \\
\text { - Workplace visit; mapping personal resources in interaction with the work environment, work } \\
\text { training. } \\
\text { - Clarify function and working ability on the basis of the mapping, work place-based intervention. } \\
\text { - Return to work planning in cooperation with the employer and other collaboration partners. }\end{array}$ & $\begin{array}{l}6 \text { hours a day, } \\
\text { I-3 days a week } \\
\text { for } 52 \text { weeks }\end{array}$ \\
\hline $\begin{array}{l}\text { During/after } \\
\text { finishing the } \\
\text { rehabilitation period }\end{array}$ & $\begin{array}{l}\text { Follow-up activities: in addition to the regular rehabilitation program (57 weeks), the } \\
\text { rehabilitation center offers group-based education/training eg, endurance groups, water activity } \\
\text { groups, and relaxation training groups in the participant's local community in order to maintain } \\
\text { or improve functioning in daily life. }\end{array}$ & $\begin{array}{l}\text { I hour I-3 days } \\
\text { a week - continuous }\end{array}$ \\
\hline
\end{tabular}

are included. Individual items are scored from $0-3$ or 3-0, depending on the direction of the wording of the items. An optimal balance between sensitivity and specificity seems to be achieved when caseness is defined by a score of $\geq 8$ on both the anxiety and depression subscales of the HADS. ${ }^{18}$

\section{Physical function assessments}

Four aspects of physical functioning (muscle strength, endurance capacity, mobility, and balance) and degree of physical pain were measured with single items on a visual analog scale (VAS). The use of VAS in employees with musculoskeletal disorders is well-established, and single-item measures frequently perform almost as well as multi-item scales. ${ }^{19,20}$

The VAS is a line $10 \mathrm{~cm}$ in length where agreement or disagreement represents a continuum of the specific physical function measured. The VAS variables were individually measured and scored in millimeters (0-100). The participants were asked to rate the present condition/symptoms through the following questions:

- Pain experience - On a scale from 0-100 where 0 is "not troublesome at all" and 100 is "extremely troublesome", how troublesome do you experience the pain to be in everyday life?
- Muscle strength - On a scale from 0-100 where 0 is "extremely poor" and 100 is "extremely good", how do you consider your muscle strength to be? 21,22 $^{2}$

- Endurance capacity - On a scale from 0-100 where 0 is "extremely poor" and 100 is "extremely good", how do you consider your endurance capacity to be? $?^{21,22}$

- Mobility - On a scale from 0-100 where 0 is "very limited flexibility" and 100 is "very flexible", how flexible do you consider your muscles and joints to be? $?^{21,22}$

- Balance - On a scale from 0-100 where 0 is "extremely poor" and 100 is "extremely good", how do you consider your balance to be? $?^{21,22}$

Physical fitness was measured through the validated COOP/WONCA charts ${ }^{23}$ by the following question: "During the past two weeks, what was the hardest physical activity you could do for at least 2 minutes?" The answering categories consist of a 5-point ordinal scale ranging from 1 (very heavy) to 5 (very light).

Age was used as a continuous variable, and marital status was measured as a dichotomous variable (married/cohabiting versus unmarried/divorced).

\section{Return to work}

Disability status was registered in the following categories: rehabilitation benefit, vocational rehabilitation, part time 
work/rehabilitation benefit, sick leave, part-time disability pension, disability pension, social assistance, students, or unemployed. Further, the participants were categorized in "active" and "passive" strategies for work ability and work re-entry. Participants who reported working on a part-time or full-time basis were categorized as "active" and coded as "on their way into/in" work (RTW), as were individuals in job retraining or an education program. These latter two variables were categorized as "active" strategies by means of representing levels of functioning that in some ways mirror the work environment and bring forward work-related behavior in the participants - eg, they have to go somewhere on a daily basis and keep functioning at a relatively consistent level. The participants still on sick leave, receiving disability pension, or applying for disability pension after completing the 57-week multidisciplinary rehabilitation program were categorized as "passive" and coded as "on their way out/out" of work (non-RTW). The reason for this choice was that most participants in the rehabilitation program already had been on sick leave for several months before entering the 57-week rehabilitation program. Thus it was very likely that those still on sick leave after 57 weeks were in the initial phase of the process of being granted a disability pension. The dependent variable RTW was self-reported and defined by being "on their way into/in" work.

\section{Statistical analyses}

A Student's $t$-test for independent samples (continuous variables) and chi-square test (categorical variables) were used to compare those who were returning to work and those who were not. Bivariate associations between each domain of physical function and RTW were assessed through logistic regression models, estimating odds ratio (OR) with 95\% confidence intervals (CI). IBM SPSS Statistics 20 (IBM Corporation, Armonk, NY, USA) was used for the statistical analyses.

\section{Results}

In total, 566 participants completed the 57-week multidisciplinary rehabilitation program. The mean duration of pain prior to entering the rehabilitation program was 15 years (ranging from 3 months to 36 years). Most of the participants, $89.5 \%(n=505)$, reported pain in more than one location, with lower back, shoulders, and neck being the most common. To ensure that none of the participants were in any initial phase of retirement, we excluded those aged 60 years and older $(n=142)$. Further, to assess any difference in physical function and return to work among those with comorbid depressive symptoms at the end of the rehabilitation, we included only those with high depressive symptoms measured by the Hospital Anxiety and Depression Scale (HADS). The final sample consisted of 92 persons $(21.7 \%$ of all participants $<60$ years) with chronic musculoskeletal disorders and comorbid depression under 60 years of age who had undergone the 57-week multidisciplinary rehabilitation program. Of these, 70 were returning to work (RTW) and 22 were not (non-RTW).

All participants included in the present study had a HADS depression score $\geq 8$ at the end of the rehabilitation. There were no dropouts from the rehabilitation program during the investigation period.

There were no differences between the "on their way into/in work" group (RTW) and the "on their way out/out of work" group (non-RTW) in terms of age, marital status, level of depression above the cut-off value of 8 , anxiety level, and pain experience (Table 2). Muscle strength, endurance capacity, mobility, balance, and physical fitness were significantly better among those who were not returning to work.

In the bivariate analyses, four of the five domains of physical functioning measured by VAS (muscle strength, mobility, balance, and physical fitness) were significantly negatively associated with RTW, indicating that better physical functioning was associated with not returning to work (Table 3).

Among those with better function on muscle strength (OR $0.61,95 \%$ CI $0.45-0.83$ ), mobility (OR $0.73,95 \%$ CI $0.57-0.95$ ), and balance (OR $0.67,95 \%$ CI $0.50-0.91$ ),

Table 2 Characteristics of participants with chronic musculoskeletal pain and comorbid depression returning to work and not returning to work after 57 weeks of multidisciplinary rehabilitation

\begin{tabular}{llll}
\hline & $\begin{array}{l}\text { RTW } \\
(\mathbf{n = 7 0 )}\end{array}$ & $\begin{array}{l}\text { NRTW } \\
(\mathbf{n}=\mathbf{2 2})\end{array}$ & P-value \\
\hline Age in years, mean (SD) & $47.7(7.1)$ & $44.4(8.5)$ & 0.079 \\
Sex (\% women) & 61.4 & 63.8 & 0.852 \\
Civil status (\% married) & 61.4 & 72.7 & 0.335 \\
HADS-depression, mean (SD) & $10.0(2.2)$ & $9.9(1.8)$ & 0.902 \\
HADS-anxiety, mean (SD) & $12.5(3.8)$ & $12.9(4.3)$ & 0.660 \\
Pain experience, mean (SD) & $7.0(3.2)$ & $7.1(1.5)$ & 0.929 \\
Muscle strength, mean (SD) & $3.6(1.8)$ & $5.4(2.2)$ & $<0.00 I^{* *}$ \\
Endurance capacity, mean (SD) & $3.1(1.8)$ & $4.1(2.2)$ & $0.037^{*}$ \\
Mobility, mean (SD) & $3.4(I .8)$ & $4.7(2.4)$ & $0.006^{* *}$ \\
Balance, mean (SD) & $4.1(1.8)$ & $5.3(2.2)$ & $0.015^{*}$ \\
Physical fitness, mean (SD) & $3.2(1.0)$ & $2.6(I .1)$ & $0.026^{*}$ \\
\hline
\end{tabular}

Notes: Differences in means were assessed by Student's $t$-test and differences in proportions were assessed with chi-squared test. *Significant at $P<0.05$; **significant at $P<0.01$.

Abbreviations: RTW, returning to work; NRTW, not returning to work; SD, standard deviation; HADS, Hospital Anxiety and Depression Scale. 
Table 3 Bivariate associations between measurements of physical function and the dependent variable "return to work" ( $n=70)$ after multidisciplinary rehabilitation among participants with chronic musculoskeletal pain and HADS-depression $\geq 8(n=92)$

\begin{tabular}{|c|c|c|c|c|c|c|}
\hline $\begin{array}{l}\text { Independent } \\
\text { variable }\end{array}$ & $\begin{array}{l}\text { B (log } \\
\text { odds) }\end{array}$ & SE & Wald & OR & $P$-value & $95 \% \mathrm{Cl}$ \\
\hline Muscle strength & -0.480 & 0.141 & 1.61 & 0.62 & $0.001 * *$ & $0.47-0.82$ \\
\hline Constant & 3.287 & 0.727 & 20.43 & 26.77 & $0.00 I^{* *}$ & \\
\hline $\begin{array}{l}\text { Endurance } \\
\text { capacity }\end{array}$ & -0.255 & 0.125 & 4.130 & 0.78 & $0.042^{*}$ & $0.61-0.99$ \\
\hline Constant & 2.080 & 0.542 & 14.73 & 8.002 & $0.001 * *$ & \\
\hline Mobility & -0.323 & 0.125 & 6.640 & 0.72 & $0.010^{*}$ & $0.57-0.93$ \\
\hline Constant & 2.456 & 0.594 & 17.07 & 11.65 & $0.001 * *$ & \\
\hline Balance & -0.305 & 0.130 & 5.492 & 0.74 & $0.019 *$ & $0.57-0.95$ \\
\hline Constant & 2.581 & 0.688 & 14.08 & 13.22 & $0.001 * *$ & \\
\hline Physical fitness & 0.516 & 0.239 & 4.688 & 1.68 & $0.030^{*}$ & $1.05-2.68$ \\
\hline Constant & -0.331 & 0.704 & 0.222 & 0.718 & 0.638 & \\
\hline
\end{tabular}

Notes: ORs in bold with $95 \%$ Cls. $*$ Significant at $P<0.05$; **significant at $P<0.01$. Abbreviations: n, number; HADS, Hospital Anxiety and Depression Scale; SE, standard error; $\mathrm{OR}$, odds ratio; $\mathrm{Cl}$, confidence interval.

the odds of being on an active work re-entry strategy were $23 \%-39 \%$ lower compared with those with poorer physical function. The same pattern was seen for physical fitness measured by the COOP/WONCA charts (OR 1.75, $95 \% 1.07-2.99$ ), indicating that the odds of returning to work were $75 \%$ lower among those who reported that they were able to perform hard physical activity for at least 2 minutes. In other words, each of these measures of physical functioning was worse among those reporting that they were on an active strategy for work re-entry. Endurance capacity (OR 0.77, 95\% CI 0.58-1.03) did not reach any statistical association with RTW; even so, the OR of 0.77 ( $P=0.076)$ indicated that this result was in line with the other results and it would probably have become statistically significant in a larger sample.

\section{Discussion}

In this study of persons with chronic musculoskeletal disorders and comorbid depression, we found higher levels of physical functioning to be significantly associated with non-RTW at the end of the rehabilitation period of 57 weeks. Given that the multidisciplinary rehabilitation program in this study places a strong emphasis on function and work ability, our results are somewhat surprising. Additionally, we have not been able to find other studies confirming our results or the opposite; that individuals with chronic musculoskeletal disorders and comorbid depression returning to work have better physical function compared with those who are depressed not returning to work. In the present study, there were no differences in pain experience or severity of depression between those returning and those not returning to work. Hence, there are no straightforward explanations of our findings of reduced odds of RTW among those with best physical functioning. In the following discussion we present two important aspects that may be relevant to our findings.

\section{Physical functioning versus occupational functioning}

Physical functioning can be defined in different ways. Physical limitations, physical ability and physical activity are all domains covering different aspects of human physical functioning. Most studies on mental health and physical function suggest an inverse association between decreasing levels of depressive symptoms and increasing physical functioning. However, an exhaustive literature review showed that the association between depressive symptoms and physical functioning is unexpectedly weak. ${ }^{16}$ This may be due to low consensus on what physical measurement to use, and whether such measures should be performance-based or patient-reported. Bean et $\mathrm{a}^{24}$ found that self-reported measures of physical function were associated with psychosocial factors such as depression, while performance-based measures were not. Nevertheless, the former study was among elderly persons with mobility limitations and results cannot be generalized to the sample in our study.

An alternative explanation for the association found in the present study is that self-report of physical functioning may be influenced by psychological distress. Despite participation in an occupational rehabilitation program, some employees may lack motivation to return to a certain workplace. In a qualitative study of disability pensioners with chronic back pain, Magnussen et $\mathrm{al}^{25}$ found that some of the barriers related to RTW were earlier negative work experiences, poor self-judgment of work ability, and low self-esteem. Further, many of the participants pointed to conditions at their former workplaces that they believed contributed to the disability process and that would make it difficult to return to work. Hence, the experience of being granted a disability pension, which means not returning to work, might be followed by the feelings of relief and satisfaction, while those, by definition, "on their way into work" might be subjected to remaining in an unsafe and uncertain situation, both economically and occupationally. In turn, this emotional state may directly affect one's evaluation of physical functioning, despite being depressed. Several studies support that the RTW is a multifactorial process ${ }^{8}$ and that physical functioning should not be mixed up with occupational functioning. Occupational functioning is more than being able to perform certain tasks at 
work, ${ }^{26}$ as it also involves non-job-specific behaviors such as cooperation and dedication. Thus, occupational functioning can be related to factors at the individual level, at the group level, and at the organizational level.

Nevertheless, according to the literature most psychosocial interventions to achieve optimal rehabilitation outcomes in employees with musculoskeletal pain have focused on risk factors within the individual (eg, pain catastrophizing and expectancies) and not on relevant factors at the workplace, such as interpersonal conflicts or job stress (at the group or institutional level). ${ }^{27}$ In the vast majority of observational studies on factors related to the RTW process, as in this study as well, psychosocial interventions did not follow common evidence-based guidelines or treatment protocols. ${ }^{27,28} \mathrm{In}$ turn, this makes any evaluation of treatment outcome after rehabilitation difficult, especially regarding assessment of interventions that focus on work-related factors "outside" of the individual. ${ }^{27}$

Further, depression affects several areas related to occupational functioning, such as absenteeism, education, and employment opportunities. Depressed workers also report more conflicts and negative social outcomes. ${ }^{16}$ In a qualitative study of factors relevant in the assessment of the RTW process of employees on long-term sickness absence due to a depressive disorder, Muijzer et $\mathrm{al}^{4}$ found that physical functioning, attitudes, competence, and environmental factors such as "employer-employee relationship" have implications for the RTW process. The study was, however, based on focus-group interviews with labor experts working at the Social Insurance Institute in the Netherlands. In a recent Swedish study, Sjöstrøm et al $^{9}$ evaluated a 7-week multidisciplinary rehabilitation program in patients with musculoskeletal pain, with emphasis on mental symptoms measured by the HADS. They found that, even if stress levels improved, those with full-time sick leave showed no changes in anxiety and depression levels during the 2-year study period. According to the authors, the results indicate that persons with musculoskeletal pain and comorbid psychological distress may require rehabilitation with different content than that given to employees with low psychological symptoms. In a recent systematic review of factors associated with work participation and work functioning in depressed workers, Lagerveld et $\mathrm{al}^{29}$ found that work-related and personal factors were less frequently studied. Further, the authors stated that gaps in knowledge exist on factors predictive of work participation and work functioning in depressed workers. These results illustrate that the RTW process among depressed employees with musculoskeletal conditions is multifactorial and not merely a result of physical functioning or pain severity.

\section{Somatic versus mental health as barriers to RTW}

Psychosocial factors are important contributors to work disability associated with chronic musculoskeletal pain. Epidemiological studies from The Nord-Trøndelag Health Study in Norway suggest that approximately one-third of individuals reporting somatic health problems also have anxiety disorder and/or depression ${ }^{30}$ and that a statistical relationship exists between anxiety, depression, and functional somatic symptoms, independent of age and sex. ${ }^{6}$ At the same time, medical examination of patients with chronic musculoskeletal pain often fails to demonstrate any organic diseases. ${ }^{15}$ In a Norwegian population-based cohort study, Mykletun et al ${ }^{31}$ found anxiety and depression to be strongly and independently associated with disability pensions granted for physical conditions and diagnoses, suggesting that administrative data may have underestimated the contribution of mental disorders to the awarding of disability pensions.

The latter findings are partly supported by a recently published Swedish study ${ }^{28}$ of biopsychosocial functioning and assessment of the ability to work in 174 patients on long-term sick leave due to chronic musculoskeletal pain. All patients underwent orthopedic assessment of physical function and ability to work; 83 were referred for psychiatric evaluation of diagnosis and function. The final evaluation involved the orthopedist and the psychiatrist working together as a team to form a mutual opinion of the patients functional, physical, and psychological abilities in relation to occupational demands and the prognosis for returning to work. Interestingly, the main cause of sick leave changed from a somatic diagnosis to a psychiatric diagnosis in $69 \%$ of patients. Of these, $33 \%$ were considered not able to return to work. According to the authors, ${ }^{28}$ the study sheds light on the limitations related to the assessment of ability to work, because physicians, lacking an established medical protocol, evaluate the patient according to their own experience. Further, inadequate assessment of work ability may lead to marginalization and isolation. Inappropriate assessment of work ability leads to the wrong choice of interventions, which may employ and maintain unethical practices regarding the RTW process in employees with chronic musculoskeletal pain and comorbid depression.

Depression and pain share biological pathways and neurotransmitters, which has implications for the treatment. Additionally, psychiatric disorders in patients 
with chronic musculoskeletal pain have commonly been undiagnosed. ${ }^{32}$ The combination of depression and pain is associated with worse clinical outcomes than either condition alone. Thus, a treatment model that incorporates treatment of both depression and pain seems necessary for more optimal outcomes. ${ }^{33}$ Pain is also a subjective sensory experience that is closely associated with affect, cognition, and aspects of the employee's social environment. Thus, it is possible that depressive symptoms may act both as a cause and as a consequence of chronic musculoskeletal pain and absence from work. Further, it is possible, although not necessarily the case, that work-related factors are significantly involved in this complex process. According to the literature, ${ }^{16}$ few studies exist on the bidirectional relationship between depression and occupational functioning. In a recent evaluation of a Swedish 7-week rehabilitation program, Sjöström et $\mathrm{al}^{9}$ followed 60 participants with musculoskeletal pain for a period of up to 2 years. They found that the ten participants with fulltime sick leave (absence from work for medical reasons) during the study period showed improved stress levels but no change in anxiety and depression levels (assessed by the HADS). This group also had higher pain ratings and higher subjective disability ratings during the rehabilitation program than did those with no sick leave or those on part-time sick leave. The study illustrates that mental health problems and musculoskeletal pain are interrelated and that traditional multidisciplinary rehabilitation may not meet any special needs of this selected group.

The present study has several limitations that need to be considered. The data were collected from a relatively small sample from one rehabilitation program. All data are self-reported; thus, it is not possible to confirm whether participants actually did return to work or not. Given the use of perceived measures, one might argue that it is uncertain whether the results are indicative of physical ability or rather perception of ability. Further, we had no information on medical diagnoses or daily use of prescribed drugs. Still, as we found no difference in pain experience between those returning to work and those not returning to work, it is unlikely that the better physical functioning was due to the experience of less pain among those not returning to work. The HADS is useful in the assessment of symptoms of depression and anxiety; however, it is not validated as a diagnostic tool for clinical diagnoses in accordance with the International Classification of Diseases and the Diagnostic and Statistical Manual of Mental Disorders, fourth edition. ${ }^{34}$ The influence of occupational history, such as if the participants were unemployed or if they held a temporary or a permanent occupation position, may influence the results, but these factors were not taken into account in our study. In addition, the cross-sectional design of this study makes it impossible to make any inference on causality. However, the main focus of this investigation was to assess the association between physical function and RTW among participants with chronic musculoskeletal pain with elevated depressive symptoms at the end of a multidisciplinary rehabilitation program.

Nevertheless, $22 \%$ of those younger than 60 years participating in this 57-week multidisciplinary rehabilitation program had elevated depressive symptoms at the end of the program. It is possible that these participants constitute a marginalized group consisting of those who have had the longest duration of musculoskeletal pain and the longest sick leave prior to their participation in the multidisciplinary program. This, however, gives reason to speculate whether the evaluation of the ability to work may not have taken mental health status into account prior to or during participation in the multidisciplinary rehabilitation program. Further, and in line with the suggestions from Sjöström et al, ${ }^{9}$ it is possible that this selected group of individuals with elevated depressive symptoms may require rehabilitation with different content other than what is usually offered through a traditional multidisciplinary rehabilitation program.

\section{Conclusion}

The findings of higher physical functioning among depressed employees not returning to work after participating in a multidisciplinary rehabilitation program in this study illustrate that self-reported physical functioning does not act as a proxy for occupational functioning in the RTW process. According to the literature, there is a need for more research on the bidirectional association between depression and occupational functioning. Further, recent studies suggest that there is a need for standardized procedures in the evaluation of the ability to work and that this procedure needs to take mental health status into account. Longitudinal studies with the use of different registries (employment history, sick leave, and use of prescribed drugs) should preferably be used in the evaluation of factors promoting the RTW process among people with chronic musculoskeletal disorders and poor mental health.

\section{Disclosure}

The authors have no conflicts of interest to declare in respect of this work. 


\section{References}

1. Norwegian Institute of Public Health. The Status of Public Health in Norway 2010 - report [homepage on the Internet]. Oslo, Norway: Norwegian Institute of Public Health; 2013. Available from: http://www. fhi.no/eway/default.aspx?pid=240\&trg=Content_6899\&Main_6664=6 898:0:25,7524:1:0:0:::0:0\&Content_6899=6729:84298::1:6890:1:::0:0. Accessed November 26, 2013.

2. Murray CJ, Vos T, Lozano R, et al. Disability-adjusted life years (DALYs) for 291 diseases and injuries in 21 regions, 1990-2010: a systematic analysis for the Global Burden of Disease Study 2010. Lancet. 2012;380(9859):2197-2223.

3. World Health Organization. Depression. Fact sheet N`369 [homepage on the Internet]. Geneva, Switzerland: World Health Organization; 2013 [updated October 2012]. Available from: http://www.who.int/ mediacentre/factsheets/fs369/en/. Accessed November 26, 2013.

4. Muijzer A, Brouwer S, Geertzen JH, Groothoff JW. Exploring factors relevant in the assessment of the return-to-work process of employees on long-term sickness absence due to a depressive disorder: a focus group study. BMC Public Health. 2012;12:103.

5. Lépine JP, Briley M. The increasing burden of depression. Neuropsychiatr Dis Treat. 2011;7(Suppl 1):3-7.

6. Haug TT, Mykletun A, Dahl AA. The association between anxiety, depression, and somatic symptoms in a large population: the HUNT-II study. Psychosom Med. 2004;66(6):845-851.

7. Magni G, Moreschi C, Rigatti-Luchini S, Merskey H. Prospective study on the relationship between depressive symptoms and chronic musculoskeletal pain. Pain. 1994;56(3):289-297.

8. Sullivan MJL, Simmonds M, Velly A. Pain, depression, disability and rehabilitation outcomes - revised version [homepage on the Internet]. Montréal, Canada: Institut de recherche Robert-Sauvé en santé et en sécurité du travail (IRSST); 2010. Available from: http://www.irsst. qc.ca/en/-irsst-publication-pain-depression-disability-rehabilitationoutcomes-r-675.html. Accessed November 26, 2013.

9. Sjöström R, Asplund R, Alricsson M. Back to work: evaluation of a multidisciplinary rehabilitation program with emphasis on mental symptoms; A two-year follow up. J Multidiscip Healthc. 2012;5:145-151.

10. Gatchel RJ, Peng YB, Peters ML, Fuchs PN, Turk DC. The biopsychosocial approach to chronic pain: scientific advances and future directions. Psychol Bull. 2007;133(4):581-624.

11. Sjöström R, Alricsson M, Asplund R. Back to work - evaluation of a multidisciplinary rehabilitation programme with emphasis on musculoskeletal disorders. A two-year follow-up. Disabil Rehabil. 2008;30(9):649-655.

12. Hildebrandt J, Pfingsten M, Saur P, Jansen J. Prediction of success from a multidisciplinary treatment program for chronic low back pain. Spine (Phila Pa 1976). 1997;22(9):990-1001.

13. Vowles KE, Gross RT, Sorrell JT. Predicting work status following interdisciplinary treatment for chronic pain. Eur J Pain. 2004;8(4): $351-358$.

14. Tomey K, Sowers MR, Harlow S, Jannausch M, Zheng H, Bromberger J. Physical functioning among mid-life women: associations with trajectory of depressive symptoms. Soc Sci Med. 2010;71(7):1259-1267.

15. Holtedahl R. [Health condition in patients who apply for disability pension]. Tidsskr Nor Laegeforen. 2006;126(20):2654-2657. Norwegian.

16. McKnight PE, Kashdan TB. The importance of functional impairment to mental health outcomes: a case for reassessing our goals in depression treatment research. Clin Psychol Rev. 2009;29(3): 243-259.

17. Holzberg AD, Robinson ME, Geisser ME, Gremillion HA. The effects of depression and chronic pain on psychosocial and physical functioning. Clin J Pain. 1996;12(2):118-125.
18. Bjelland I, Dahl AA, Haug TT, Neckelmann D. The validity of the Hospital Anxiety and Depression Scale. An updated literature review. J Psychosom Res. 2002;52(2):69-77.

19. McDowell I. Measuring Health: A Guide to Rating Scales and Questionnaires. 3rd ed. New York, NY: Oxford University Press, Inc; 2006.

20. Boonstra AM, Schiphorst Preuper HR, Reneman MF, Posthumus JB, Stewart RE. Reliability and validity of the visual analogue scale for disability in patients with chronic musculoskeletal pain. Int $J$ Rehabil Res. 2008;31(2):165-169.

21. Staal JB, Rainville J, Fritz J, van Mechelen W, Pransky G. Physical exercise interventions to improve disability and return to work in low back pain: current insights and opportunities for improvement. J Occup Rehabil. 2005;15(4):491-505.

22. Braathen TN, Veiersted KB, Heggenes J. Improved work ability and return to work following vocational multidisciplinary rehabilitation of subjects on long-term sick leave. J Rehabil Med. 2007;39(6):493-499.

23. Bentsen BG, Natvig B, Winnem M. Questions you didn't ask? COOP/ WONCA Charts in clinical work and research. World Organization of Colleges, Academies and Academic Associations of General Practitioners/Family Physicists. Fam Pract. 1999;16(2):190-195.

24. Bean JF, Olveczky DD, Kiely DK, LaRose SI, Jette AM. Performancebased versus patient-reported physical function: what are the underlying predictors? Phys Ther. 2011;91(12):1804-1811.

25. Magnussen L, Nilsen S, Råheim M. Barriers against returning to work - as perceived by disability pensioners with back pain: a focus group based qualitative study. Disabil Rehabil. 2007;29(3):191-197.

26. Brollier C, Hawkins Watts J, Bauer D, Schmidt W. A content validity study of the assessment of occupational functioning. Occupational Therapy in Mental Health. 1989;8(4):29-47.

27. Sullivan MJ, Feuerstein M, Gatchel R, Linton SJ, Pransky G. Integrating psychosocial and behavioral interventions to achieve optimal rehabilitation outcomes. J Occup Rehabil. 2005;15(4):475-489.

28. Olaya-Contreras P, Styf J. Biopsychosocial function analyses changes the assessment of the ability to work in patients on long-term sick-leave due to chronic musculoskeletal pain: the role of undiagnosed mental health comorbidity. Scand J Public Health. 2013;41(3):247-255.

29. Lagerveld SE, Bültmann U, Franche RL, et al. Factors associated with work participation and work functioning in depressed workers: a systematic review. J Occup Rehabil. 2010;20(3):275-292.

30. Stordal E, Bjelland I, Dahl AA, Mykletun A. Anxiety and depression in individuals with somatic health problems. The Nord-Trøndelag Health Study (HUNT). Scand J Prim Health Care. 2003;21(3):136-141.

31. Mykletun A, Overland S, Dahl AA, et al. A population-based cohort study of the effect of common mental disorders on disability pension awards. Am J Psychiatry. 2006;163(8):1412-1418.

32. Salmi P, Svedberg P, Hagberg J, Lundh G, Linder J, Alexanderson K. Multidisciplinary investigations recognize high prevalence of comorbidity of psychiatric and somatic diagnoses in long-term sickness absentees. Scand J Public Health. 2009;37(1):35-42.

33. Bair MJ, Robinson RL, Katon W, Kroenke K. Depression and pain comorbidity: a literature review. Arch Intern Med. 2003;163(20): 2433-2445.

34. AllPsych Online. Psychiatric disorders. Diagnostic and Statistical Manual of Mental Disorders, Fourth Edition (DSM-IV) [homepage on the Internet]. West Palm Beach, FL: Heffner Media Group, Inc; 2003 [updated November 29, 2011]. Available from: http://allpsych.com/ disorders/dsm.html. Accessed November 26, 2013. 


\section{Publish your work in this journal}

The Journal of Multidisciplinary Healthcare is an international, peerreviewed open-access journal that aims to represent and publish research in healthcare areas delivered by practitioners of different disciplines. This includes studies and reviews conducted by multidisciplinary teams as well as research which evaluates the results or conduct of such teams or healthcare processes in general. The journal covers a wide range of areas and welcomes submission from practitioners at all levels, from all over the world. The manuscript management system is completely online and includes a very quick and fair peer-review system. Visit http://www.dovepress.com/testimonials.php to read real quotes from published authors.

Submit your manuscript here: http://www.dovepress.com/journal-of-multidisciplinary-healthcare-journal 